\title{
FORECASTING INTERNATIONAL TOURIST ARRIVALS IN MALAYSIA USING SARIMA AND HOLT-WINTERS MODEL
}

\author{
Norliana Mohd Lip ${ }^{1}$, Nur Shafiqah Jumery ${ }^{2}$, Fatin Amira Ahmad Termizi ${ }^{3}$, Nurul Atiqa Mulyadi ${ }^{4}$, \\ Norhasnelly Anuar ${ }^{5}$, Hanafi Ithnin ${ }^{6}$
}

1 Faculty of Computer and Mathematical Sciences, Universiti Teknologi MARA (UiTM), Seremban Campus, Malaysia.

Email: norliana7287@uitm.edu.my

2 Faculty of Computer and Mathematical Sciences, Universiti Teknologi MARA (UiTM), Seremban Campus, Malaysia.

3 Faculty of Computer and Mathematical Sciences, Universiti Teknologi MARA (UiTM), Seremban Campus, Malaysia.

4 Faculty of Computer and Mathematical Sciences, Universiti Teknologi MARA (UiTM), Seremban Campus, Malaysia.

5 Faculty of Computer and Mathematical Sciences, Universiti Teknologi MARA (UiTM), Seremban Campus, Malaysia.

$6 \quad$ Agensi Nuklear Malaysia, Bangi, Malaysia.

Email: hanafizik@gmail.com.my

\section{Article Info:}

\section{Article history:}

Received date:05.01.2020

Revised date: 04.02.2020

Accepted date: 06.02.2020

Published date: 13.03.2020

\section{To cite this document:}

Lip, N. M., Jumery, N. S., Termizi, F. A. A., Mulyadi, N. A., Anuar, N., \& Ithnin, H. (2020). Forecasting International Tourist Arrivals in Malaysia using Sarima and HoltWinters Model. Journal of Tourism, Hospitality and Environment Management, 5 (18), 41-51.

DOI: $10.35631 /$ JTHEM.518004.

\section{Abstract:}

Tourism can be described as the activities of visitors who make a visit to the main destination outside their usual environment for less than a year for any purpose. The tourism industry has become one of the influential sectors in global economic growth. Thus, tourism forecasting plays an important role in public and private sectors concerning future tourism flows. This study is an attempt to determine the best model in forecasting the international tourist's arrival in Malaysia based on Box-Jenkins and Holt-Winters model. The comparison of the accuracy of the techniques between Box-Jenkins SARIMA and Holt-Winters model was done based on the value of Mean Square Error (MSE), Root Mean Square Error (RMSE) and Mean Absolute Percentage Error (MAPE). The secondary time series data were obtained from the Tourism Malaysia Department, which consists of a number of tourist arrivals from Singapore, Korea, and the United Kingdom from the year 2013 until the year 2017. The findings of this study suggest that the SARIMA and Holt-Winters model are suitable to be used in forecasting tourist arrivals. This study found that the Holt-Winters model is the appropriate model to forecast tourist arrivals from the United Kingdom (UK) and Korea. While SARIMA $(1,1,1)(1,1,1) 12$ is the appropriate model for forecasting tourist arrivals from Singapore. 


\section{Introduction}

Tourism is one of the major contributing sectors for economic growth. The demand of tourism is affected by several factors for example travelling cost, accommodation, and climate. The process of forecasting needs to be carried on involving these factors. However, this study aims to create the forecasting model based on time series analysis which focused on the previous pattern of tourist arrivals in Malaysia.

Forecasting is one of the main activities in most large-scale business and non-business organizations. Forecasting is the whole process to acquire the methods needed to achieve future value that can be utilized as input to the goals the aims of the firm. As a decision maker, forecasting acts as a scanning device that capture incoming future signals based on previous events or other relevant circumstances that are believed to determine the outcome of events of interest. The information provided allows the firm to engage an appropriate action to change existing plans to satisfy the anticipated environmental change. With this, it can prevent the future losses.

Forecasting techniques can be generally separated into two cases which are qualitative technique and quantitative technique. Qualitative technique known as subjective prediction or opinion. Generally, it will be used when the data is scarce or insufficient in order to produce a mathematical model. Basically, quantitative technique is statistical, and it is easily evaluated with precision using a certain size criterion. This study applied quantitative technique since the data used is a time series where the future value is evaluated from a series of previous data.

There are two ways in describing a time series data which are descriptive or mathematical form. In descriptive form, the time series data refer to 'a set of information collected or arranged in a chronological succession of order over a successive equal increment in time'. The second definition can be putted in more compact mathematical term. A series can be defined by the value $y_{1}, y_{2}, y_{3}, \ldots, y_{t}$ of a set of data series called $Y$, at time $t(t=1,2,3, \ldots, t, t+1, t+$ $2, \ldots, T)$ respectively, where $T$ is the total length of the series. By way of explanation, $T$ can be considered as the sample size of the data series and that $Y$ may be represented the variable name and $y_{t}$ the value of the observation at time, $t$. More specifically, this study is aimed to investigate $y_{t}, t=1,2,3,4, \ldots, T$ represented a series of $\mathrm{T}$ observations recorded over $\mathrm{T}$ time interval (Lazim, 2013).

In general, time series data is analysed to achieve two main objectives. The main purpose is to diagnose and express the basic structure and phenomenon as described by the observation sequence in the series. The second purpose is based on the data obtained in the first objective that induce the appropriate mathematical model to accommodate the data series and then applies the model to produce the predictive value. The primary target of this study is to compare the two techniques which are Holt- Winters and Box-Jenkins by using Mean Square Error (MSE), Root Mean Square Error (RMSE), and Mean Absolute Percentage Error (MAPE) and later on to determine the best method to forecast tourist arrivals in Malaysia from three countries which are Singapore, United Kingdom (UK) and Korea. 


\section{Literature Review}

\section{The Variable Used to Estimate Tourist Arrivals}

A variable is any factor that can be controlled or changed. There are two types of variable that commonly be used in the research which are independent variable and dependent variable. There are several variables that can be used to evaluate the prediction of tourist arrivals forecasting. According to the article by Dharmaratne (1995), a comparison of various techniques of prediction was done to criticize a 'great' one based on an accurate condition. The techniques included ARIMA models. The number of tourist arrivals that stay longer in Barbados was used as the variable.

The variable that used in the research conducted by Chu (1998) is the monthly data of the international visitor that arrived in Asian-Pacific countries from January 1975 until December 1994 in order to predict the International tourist arrivals in Asian-Pacific countries. Also, based on the study pursued by Law and Au (1999), the data series had been collected by the price of services, the average rate of hotel, the exchange rate of foreign, the number of residents in Japan, marketing expense, gross domestic expenditure and the number of tourists in order to predict the Japanese visitor in Hong Kong. Next, the article by Goh and Law (2002) used the number of tourism demand in Hong Kong due to discover whether Box-Jenkins can be estimated the model that contained a stochastic non-stationary SARIMA model and MARIMA could outperform other normally applied the time series models.

From the research conducted by Burger, Dohnal, Kathrada, and Law (2001), they used the number of Africa's tourist arrivals from United State (US) to Durban, South Africa based on the time from 1992 until 1998. Besides, a study that carried out to estimate the total number of tourist arrivals in Australia from a certain country which is Hong Kong, Malaysia and Singapore (Lim \& McAleer, 2001). The researcher collected data from Australian Bureau of Statistic which is the number of tourist arrivals by quarterly. Additionally, the case study conducted by du Preez and Witt (2003) are to make a comparison of the fit and the performance of the forecasting between the Univariate and Multivariate model in order to obtain the best adequate model. The numbers of tourist monthly data were used to achieve the aim of this study. According to the article by Shareef and McAleer (2007) mentioned the time series of monthly international visitor that arrived in the Maldives.

Besides, the research compiled by Palmer, José Montaño, and Sesé (2006), they used the expenditure of tourism in the Balearic Island (in millions of pesetas) from 1986 to 2000 for each quarter. A study conducted by Chu (2008) mentioned examining the ARAR model and its good effect as a forecasting technique for tourist arrivals in the Asian-Pacific. The number of visitors and the type of countries act as variables. Next, Athanasopoulos and Hyndman (2008) have developed 3 difference statistical models and those models are used to predict the Australian domestic tourism demand. They used the data of the number of visitor night that can be detached the data based on the important factor of take a trip. Loganathan (2010) applied the Box-Jenkins model to predict the four-step ahead based on quarterly of the International Tourism demand in Malaysia. The variable that used in the research was the number of International Tourism demand in Malaysia based on quarterly during the period of 1995-2008.

A study have been conducted by Song, Li, Witt, and Athanasopoulos (2011) is to predict the tourists arrival in Hong Kong from a certain country which were from China, South Korea, UK and USA. The researchers select the data monthly and aggregated the data by quarterly from 
1985 until 2014. Additionally, according to Kim, Wong, Athanasopoulos, and Liu (2011) the purpose of the study to appraise the performance of the prediction intervals in the context of predicting the tourism. The variable used was the monthly time series data for the total number of tourists that arrived in Hong Kong and Australia. Meanwhile, in the research conducted by Claveria and Torra (2014), the variables used are the monthly data of the stay overnight and tourist arrivals from foreign countries to Catalonia for several years, in order to analyse the tourism demand for forecasting performances based on several region. The study conducted by Peng, Song, and Crouch (2014), used the number of international tourism demand due to recognize and determine the impacts of data characteristics and learn characteristics on the estimating the accurateness. Oscar Claveria (2014) use the monthly data of tourists' arrival from January 2001 until July 2012 to predict the number of tourists.

\section{Applications of Box Jenkins Method for Forecasting Tourist Arrivals}

According to the article by (Huang \& Min, 2002), to estimate whether Taiwan tourism has recovered totally from the crisis and predicting the volume of tourist arrivals after the quake in several years. The article conducted by Smith, Williams, and Keith Oswald (2002) found that the non-parametric regression with heuristic predict generation methods was suggested to use naïve forecasting approach. The result in the study compiled by Ediger and Akar (2007) ARIMA and SARIMA models can efficiently be used for prediction of energy demand. The result in forecasting the power produced by the plant was quite good perfect in the research by Bouzerdoum, Mellit, and Massi Pavan (2013). The article conducted by Liang (2014) showed to predict the demand for tourism industry by using the proposed forecasting method, the more accurate prediction can be obtained.

Other than that, article performed by Oliveira, Steffen, and Cheung (2017) found that double seasonal ARIMA model was the best skill to know the time series structure of water demands. According to the article compiled by Bas, Ortiz, Ballesteros, and Martorell (2017) found that the higher explanatory power of SARIMA model for the long and short term than MLR model and then considered as the best forecaster of 7Be air concentrations. Seasonal ARIMA was the best method for predicting the time series of a month of rainfall data since the technique fitted the data well in the article performed by Arumugam and Saranya (2018). Last but not least, engaged in research conducted by Mao, Zhang, Yan, and Cheng (2018) the best model of SARIMA $(1,0,0)(0,1,1)_{12}$ showed that TB incidence slightly rises in several months.

\section{The Possibilities of using Holt-Winters Method for Forecasting Tourist Arrivals}

The study conducted by Grubb and Mason (2001) aimed to investigate this problem because it took long lead time for air passenger traffic on the order of ten years. They used a Holt-Winters method to generate the future prediction and explored the past behaviour. They do some modifications of Holt-Winters method and get a greatly improved for long lead-time series of forecasting performances. Then, the result is modelling assumption which was to get the particular forecast it obligates the type of historical forecast is more significant than the statistical behaviour of the model error. Besides that, the study that has been carried out for comparison of the performance of numerous simple top-down forecasting methods for predicting the noisy geographic time series to the performance of three methods which is a Naïve method, Holt-Winters method and Box Jenkins method (Huddleston, Porter, \& Brown, 2015). This study had been applied in the city of Pittsburgh over the five years which is the comparison modelling performance of produce the forecast in a regularly weeks and patrol level sector of burglaries. The result suggests that simple top-down forecasting method can provide a general-purpose method and give more accurate forecast compare with the naïve method. 
According to the study that has been performed by Ferbar Tratar and Strmčnik (2016). The researcher wants to identify which method was the best method for short and long-term heat load forecasting on the three levels, which were monthly, weekly, and daily forecasting bases. The methodology that they used in this study is Multiple and Exponential Smoothing methods. In this method, they considered the value of MSE, MAPE, MARNE and Theil's U-statistics to get the accuracy of forecasting. The result showed that multiple regressions were suitable for daily and weekly short term while the Holt-Winters method suitable for long-term heat load forecasting and monthly short-term heat load forecasting. Moreover, based on the study conducted to air passenger demand at the national case by few researchers (Dantas, Cyrino Oliveira, \& Varela Repolho, 2017). This paper was about the extension of application between Bootstrap aggregating (Bagging) and Holt-Winters method to the air transportation. The objective was to forecast the future demand for air transportation. The resulted proved that Bagging and Holt-Winters method give an improvement in forecast accuracy.

\section{Methodology}

\section{Research Goal}

In this study, we aim to compare the accuracy of the techniques between the Box-Jenkins and Holt-Winters Trend and Seasonality using Mean Square Error (MSE), Root Mean Square Error (RMSE), and Mean Absolute Percentage Error (MAPE), and to forecast the number of tourist arrivals using the best selected model.

\section{Sample and Data Collection}

The methodology starts with collection of data from secondary resources which is from Tourism Malaysia Department. The data is about tourist arrivals in Malaysia, which is from January 2013 until December 2017. This study used Microsoft Excel and E-views 7 for the Single Exponential Smoothing Technique and Box-Jenkins methodology respectively.

\section{Holt-Winters Method}

Holt-Winters are more suitable for seasonality data that also can predict the long-term forecasting. Holt-Winters consist of two assumptions, which are multiplicative effect assumption and addictive effect assumption. Multiplicative effect means if the size of the seasonal variation increases according to the increase level of the data series. Addictive effect means when the absolute size of the variation is the independent of each other. According to N. A. Elmunim, Abdullah, M., Hasbi, A. M., Bahari, S. A., (2015), the equatorial region in Malaysia is more suitable for multiplicative effect compared to addictive effect. This study focused on Multiplicative effect assumption, which contained three basic component, level, trend and seasonality component.

\section{Level component:}

$$
L_{t}=\alpha\left(\frac{Y_{t}}{S_{t}}\right)+(1-\alpha)\left(L_{t-1}+b_{t-1}\right)
$$

Trend component:

Seasonal component:

$$
b_{t}=\beta\left(L_{t}-L_{t-1}\right)+(1-\beta) b_{t-1}
$$

$$
S_{t}=\gamma\left(\frac{Y_{t}}{L_{t}}\right)+(1-\gamma) S_{t-s}
$$


The $m$-step-ahead forecast calculated as:

$$
F_{t+m}=\left(L_{t}+b_{t} \times m\right) S_{t-s+m}
$$

where $L_{t}$ is the level component, $b_{t}$ is the trend component, $S_{t}$ is the seasonal component, and $Y_{t}$ is the number of tourists arrival, while $\mathrm{t}$ is the time period for the component and $\mathrm{s}$ is the duration of seasonal. $F_{t+m}$ is the forecast value for $m$-step ahead, $m=1,2,3, \ldots$ ? The smoothing parameter $\alpha, \beta$, and $\gamma$ are the level, trend and seasonality whereas the parameter lies in the interval $[0,1]$. Before proceed with those components, all the initial value for every component need to be found. Then, it will proceed to find all those components, which are Level, Trend and Seasonality component. Initial value for the level component, $L_{0}$. Where $n$ is represents the total number of months.

$$
L_{0}=\frac{y_{1}+y_{2}+y_{3}+y_{4}+\cdots+y_{n}}{12}
$$

Initial value for the first component of trend, $b_{0}$. Where $s$ is representing the number of seasons.

$$
b_{0}=\frac{1}{s}\left(\frac{y_{s+1}-y_{1}}{s}+\frac{y_{s+2}-y_{2}}{s}+\frac{y_{s+3}-y_{3}}{s}+\cdots+\frac{y_{s+n}-y_{n}}{s}\right)
$$

Initial values of the seasonal components, $S_{0}$.

$$
S_{n}=\frac{y_{n}}{L_{0}}
$$

\section{Box-Jenkins Methodology}

This approach is introduced by George E. P. Box and Gwilym M. Jenkins. Univariate ARIMA model used the technique of analysing the time series data. At this phase, a simple data analysis carried out to comprehend the fundamental pattern that involved in the time series. The basic pattern can either be trend pattern, seasonal pattern, cyclical pattern and irregular pattern. The analysis conducted by constructing a simple graph of time for the original data obtained. The objective of this process is to ensure if there exist any unusual observations in the graph. If there exist the unusual observations, so this study needs to make a decision either want to make transformation or not beneficial to the stationary of the data.

There consists of two methods to identify if the data series is stationary. Firstly, the ACF and PACF pattern from the original data were plotted by using E-View 7 Software and observed towards the spike exist. From this stage, this study can develop ARMA (p,q) model. ARMA model is the mixed of Autoregressive (AR) model and Moving Average (MA) model. The general ARMA model refer to as an AR (p) and MA (q) where p and q refer to the order of the autoregressive and moving average, respectively.

The ARMA model can be written as:

$$
y_{t}=\mu+\emptyset_{1} y_{t-1}+\emptyset_{2} y_{t-2}+\cdots+\emptyset_{p} y_{t-p}-\theta_{1} \varepsilon_{t-2}-\cdots-\theta_{q} \varepsilon_{t-q}+\varepsilon_{t}
$$

where AR model the $\mu$ and $\emptyset_{\mathrm{j}},(j=1,2,3, \ldots, p)$ is the constant term that need to be estimated, $y_{t-1}$ is the dependent value, $y_{t-p}$ and $p^{\text {th }}$ is the lagged dependent, and $\varepsilon_{t}$ is the error term. Meanwhile, for MA model, $\mu$ is represent as the mean value which are the fluctuation series, the $\theta_{\mathrm{k}}(\mathrm{k}=1,2,3, \ldots, \mathrm{q})$ is the moving average parameters that need to be estimated and the $\varepsilon_{t}$ is the error term. This model needs to be applied backward shift operator B written as: 


$$
\begin{array}{r}
\text { Journal of Tourism, Hospitality and Environment Management (JTHEM) } \\
\text { Volume 5 Issue 18 (March 2020) PP. 41-51 } \\
\text { DOI 10/35631/JTHEM.518004 }
\end{array}
$$

where the first component $\left(1-\emptyset_{1} B-\emptyset_{2} B^{2}-\cdots-\emptyset_{P} B^{P}\right)$ represents the $\operatorname{AR}(\mathrm{p})$ and the second component $\left(1-\theta_{1} B-\theta_{2} B^{2}-\ldots-\theta_{q} B^{q}\right)$ represents the MA(q).

Second method is by conducting the Augmented Dickey Fuller (ADF) test and the result will be obtained by using the E-Views 7 software. This study need to perform the first differencing if the data series is not stationary. Since the data consist of the seasonality component, which is monthly, first seasonal differencing needs to be performed. The process of differencing is the procedure of remove the trend pattern from the actual data. The first seasonal differencing can be denoted as ' $\mathrm{D}$ ' and can be defined as:

$$
Z_{t}=y_{t}-y_{t-12}
$$

Then this study needs to perform the first non-seasonal differencing. The first non-seasonal differencing can be denoted as ' $\mathrm{d}$ ' and can be defined as:

$$
\Delta y_{t}=y_{t}-y_{t-1}
$$

Therefore, the SARIMA (p,d,q) (P, D, Q) 12 model can be formulated. This model needs to be applied backward shift operator $\mathrm{B}$ written as:

$$
\begin{aligned}
& \left(1-\emptyset_{1} B-\emptyset_{2} B^{2}-\cdots-\emptyset_{P} B^{P}\right)(1-B)\left(1-\emptyset_{1} B^{12}-\cdots-\emptyset_{P} B^{P}\right)(1- \\
& \left.B^{12}\right) y_{t}=\mu+\left(1-\theta_{1} B-\theta_{2} B^{2}-\ldots-\theta_{q} B^{q}\right)\left(1-\theta_{1} B^{12}-\ldots-\theta_{q} B^{q}\right) \varepsilon_{t}
\end{aligned}
$$

Where $(1-B)$ represents the first order non- seasonal differencing and $\left(1-B^{12}\right)$ represents the seasonal differencing.

\section{Validation of The Models}

From the several possible of SARIMA model, this study should choose the best model by validating all the possible models using the statistical test. There have three common statistical tests that can be used to validate the SARIMA model which are Akaike's Information Criterion (AIC), Bayesian Information Criterion (BIC) and Durbin Watson test.

The last evaluation to select the appropriate model in this study will based on three measurements which are Mean Square Error (MSE), Root Mean Square Error (RMSE) and Mean Absolute Percentage Error (MAPE).

The MSE is given by:

$$
M S E=\frac{\sum_{t=1}^{n} e_{t}^{2}}{n}
$$

Where, $e_{t}$ is the different between the actual value at the time $t$ and the fitted value at time $t$. While $\mathrm{n}$ is the number of forecast error terms that produced by the model.

The RMSE is given by:

$$
R M S E=\sqrt{\frac{\sum_{t=1}^{n} e_{t}^{2}}{n}}
$$

Where, $e_{t}$ is the different between the actual value at the time $t$ and the fitted value at time $t$. While $n$ is the number of forecast error terms that produced by the model. 
The MAPE is written as:

$$
\text { MAPE }=\sum_{t=1}^{n} \frac{\left|\left(e_{t} / y_{t}\right) * 100\right|}{n}
$$

Where $n$ is indicated as the value data points and $\left|\left(\frac{e_{t}}{y_{t}}\right) * 100\right|$ is indicated as the absolute percentage error that had been computed on the fitted values for a particular predicting method.

\section{Analyses and Results}

The first purpose of this study is to determine the best model between Holt-Winters and Box Jenkins method. A good forecast model is the model that has the lowest value of MSE, RMSE and MAPE.

Table 1: The Summary Result of MSE, RMSE, and MAPE for Holt-Winters and Box-

\begin{tabular}{|c|c|c|c|c|}
\hline Tourist & Models & MSE & RMSE & MAPE \\
\hline \multirow[b]{2}{*}{ Singapore } & Holt-Winters & 9069368666 & 95233 & 6.8052 \\
\hline & $\begin{array}{c}\text { SARIMA }(1,1,1) \\
(1,1,1)_{12}\end{array}$ & 1531449606 & 39133 & 2.692 \\
\hline \multirow{3}{*}{ Korea } & Holt-Winters & 33090835 & 5752 & 11.8989 \\
\hline & $\begin{array}{c}\text { SARIMA }(0,1,1) \\
(0,1,0)_{12}\end{array}$ & 229560073 & 15151 & 36.2130 \\
\hline & Holt-Winters & 14826529 & 3851 & 9.4840 \\
\hline United Kingdom & $\begin{array}{c}\text { SARIMA }(1,1,0) \\
(0,1,0)_{12}\end{array}$ & 39916327 & 6317 & 16.4603 \\
\hline
\end{tabular}

Table 1 illustrated the summary result of MSE, RMSE and MAPE for Holt-Winters and Box Jenkins model in forecasting tourist arrivals. For Singapore, the model of SARIMA $(1,1,1)$ $(1,1,1)_{12}$ has the smallest value of error for MSE, RMSE and MAPE. Therefore, SARIMA $(1,1,1)(1,1,1)_{12}$ is the better model compared to Holt-Winters in order to forecast the tourist arrivals from Singapore. The Holt-Winters model has the smallest values of error for MSE, RMSE and MAPE for tourist arrivals from Korea and United Kingdom. Therefore, it can be concluded that the Holt-Winters model is the best model to forecast the tourist arrivals from Korea and United Kingdom.

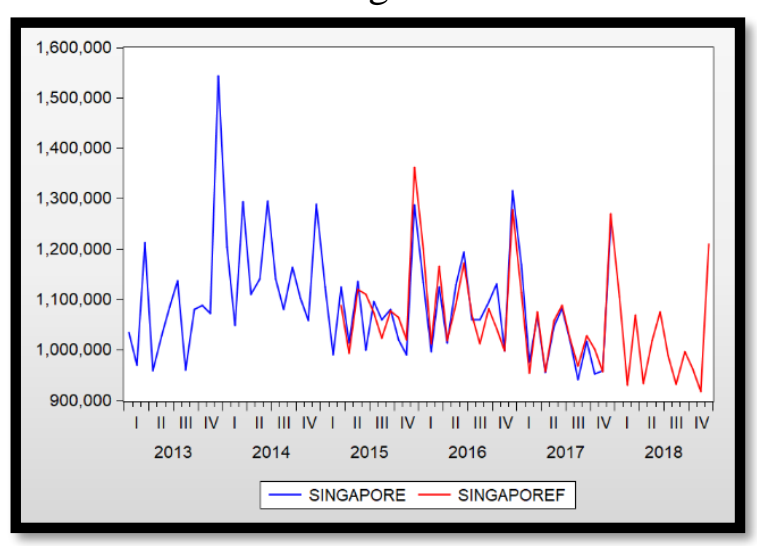

(a)

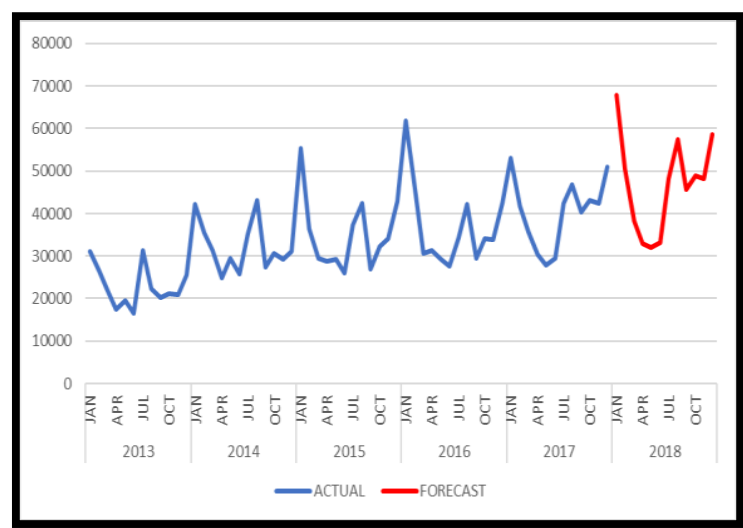

(b) 


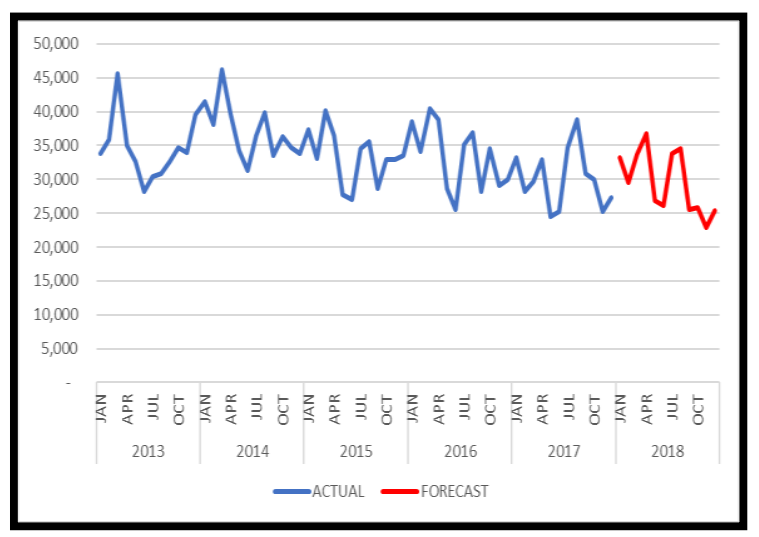

(c)

\section{Figure 1 (a)-(c): Actual Value versus Forecast Value of Tourist Arrivals from Singapore, Korea and United Kingdom Respectively}

According to figure 1(a), the blue line represents the actual data while the red line represents the forecast data for tourist arrivals from Singapore based on SARIMA $(1,1,1)(1,1,1)_{12}$ model. The graph shows the small changes between actual line and forecast line. From the observation, the pattern between actual and forecast value are nearly same. It is because the fluctuation are repeated in December. Figure (b) and (c) shows the blue line represents the actual data while the red line represents the forecast data for tourist arrivals from Korea and United Kingdom respectively. Figure (b) illustrates the trend of forecasting value is decreasing and increasing steadily throughout the year 2018 for tourist arrivals from Korea. While in figure (c), the trend of forecast value is upward and downward throughout the year 2018 for tourist arrivals from United Kingdom.

\section{Conclusion and Recommendation}

In this study, the data obtained from the Tourism Malaysia Department about the monthly data of tourist arrivals in Malaysia from January 2013 until December 2017 has been implemented. This study focused on two models in order to implement the data series which are Holt-Winters Trend and Seasonality and SARIMA model. The models can deal with time series data that consists of seasonality. Through this implementation, the comparison between these two models are conducted based on error measurements which are MSE, RMSE and MAPE. From the results, it can be proved that the Holt-Winters model also can be used in forecasting tourist arrivals. Hence, the Holt-Winters model are the appropriate model to forecast the tourist arrivals from United Kingdom and Korea. While, the SARIMA $(1,1,1)(1,1,1)_{12}$ is the appropriate model for forecasting tourist arrivals from Singapore. From the observation, it is very difficult to get the actual value of tourist arrivals since it related with the unpredicted factors such as nature disasters, economic factors and political factors. Nevertheless, this study can cater these problems in forecasting the number of tourist arrivals by analysing the previous patterns of the data. The study reveals the fact that the Holt-Winters Trend and Seasonality also can be used for time series forecasting in the cases that related with the tourist arrivals.

After all, forecasting plays the important roles in the tourism planning. Thus, it is important to ensure the forecasting is keep in track on what will happen in the future because we will never know whether the forecast value will be correct or vice versa. To find the exact value of forecasting is quite difficult because the value sometimes can be too far from the actual data. 
In order to prove the statement, the future studies can be done for the other method that related with ARIMA model such as Fuzzy Seasonal ARIMA model (FSARIMA) or for the different types of data series.

\section{References}

Arumugam. P. \& Saranya, R. (2018). Outlier Detection and Missing Value in Seasonal ARIMA Model Using Rainfall Data. Materials Today: Proceedings, 5(1, Part 1), 1791-1799.

Athanasopoulos, G., \& Hyndman, R. J. (2008). Modelling and Forecasting Australian Domestic Tourism. Tourism Management, 29(1), 19-31.

Bas, M. d. C., Ortiz, J., Ballesteros, L. \& Martorell, S. (2017). Evaluation of a Multiple Linear Regression Model and SARIMA Model in Forecasting 7Be Air Concentrations. Chemosphere, 177, 326-333.

Bouzerdoum, M., Mellit, A., \& Massi Pavan, A. (2013). A Hybrid Model (SARIMA-SVM) for Short-term Power Forecasting of a Small-Scale Grid-Connected Photovoltaic Plant. Solar Energy, 98, 226-235.

Burger, C. J. S. C., Dohnal, M., Kathrada, M., \& Law, R. (2001). A Practitioners Guide to Time Series Methods for Tourism Demand Forecasting: A Case Study of Durban, South Africa. Tourism Management, 22(4), 403-409.

Chu, F.-L. (1998). Forecasting Tourism Demand in Asian-Pacific Countries. Annals of Tourism Research, 25(3), 597-615.

Chu, F.-L. (2008). Analyzing and Forecasting Tourism Demand with ARAR Algorithm. Tourism Management, 29(6), 1185-1196.

Claveria, O., \& Torra, S. (2014). Forecasting Tourism Demand to Catalonia: Neural Networks versus Time Series Models. Economic Modelling, 36, 220-228.

Dantas, T. M., Cyrino Oliveira, F. L., \& Varela Repolho, H. M. (2017). Air Transportation Demand Forecast Through Bagging Holt-Winters Methods. Journal of Air Transport Management, 59, 116-123.

Degiannakis, S., Filis, G., \& Hassani, H. (2018). Forecasting Global Stock Market Implied Volatility Indices. Journal of Empirical Finance, 46, 111-129.

Dharmaratne, G. S. (1995). Forecasting Tourist Arrivals in Barbados. Annals of Tourism Research, 22(4), 804-818.

du Preez, J., \& Witt, S. F. (2003). Univariate Versus Multivariate Time Series Forecasting: An Application to International Tourism Demand. International Journal of Forecasting, 19(3), 435-451.

Ediger, V. Ş., \& Akar, S. (2007). ARIMA Forecasting of Primary Energy Demand by Fuel in Turkey. Energy Policy, 35(3), 1701-1708.

Elmunim, N. A., Abdullah, M., Hasbi, A. M., \& Bahari, S. A. (2017). Comparison of GPS TEC Variations with Holt-Winter Method and IRI-2012 Over Langkawi, Malaysia. Advances in Space Research, 60(2), 276-285.

Elmunim, N. A., Abdullah, M., Hasbi, A. M., Bahari, S. A.,. (2015a). The Comparison HoltWinter Models for Forecasting the Ionospheric Delay Using GPS Observation. Indian J. Radio Space Phys, 44, 28-34.

Ferbar Tratar, L., \& Strmčnik, E. (2016). The Comparison of Holt-Winters Method and Multiple Regression Method: A case study. Energy, 109, 266-276.

Goh, C., \& Law, R. (2002). Modeling and Forecasting Tourism Demand for Arrivals with Stochastic Non-Stationary Seasonality and Intervention. Tourism Management, 23(5), 499-510.

Grubb, H., \& Mason, A. (2001). Long Lead-Time Forecasting of UK Air Passengers by HoltWinters Methods with Damped Trend. International Journal of Forecasting, 17(1), 7182. 
Huang, J.-H., \& Min, J. C. H. (2002). Earthquake devastation and recovery in tourism: the Taiwan case. Tourism Management, 23(2), 145-154.

Huddleston, S. H., Porter, J. H., \& Brown, D. E. (2015). Improving forecasts for noisy geographic time series. Journal of Business Research, 68(8), 1810-1818.

Hyndman, R. J., \& Khandakar, Yeasmin. (2008). Automatic Time Series Forecasting: The Forecast Package for R. . Journal of Statistical Software, 27(3), 1-22.

Kim, J. H., Wong, K., Athanasopoulos, G., \& Liu, S. (2011). Beyond point forecasting: Evaluation of alternative prediction intervals for tourist arrivals. International Journal of Forecasting, 27(3), 887-901.

Law, R., \& Au, N. (1999). A neural network model to forecast Japanese demand for travel to Hong Kong. Tourism Management, 20(1), 89-97.

Lazim, M. A. (2013). Introductory Business Forecasting A Practical Approach $3^{\text {rd }}$ Addition. Book, 53-55.

Liang, Y.-H. (2014). Forecasting models for Taiwanese tourism demand after allowance for Mainland China tourists visiting Taiwan. Computers \& Industrial Engineering, 74, 111-119.

Lim, C., \& McAleer, M. (2001). Forecasting tourist arrivals. Annals of Tourism Research, 28(4), 965-977.

Loganathan, N. a. Y. I. (2010). Forecasting International Tourism Demand in Malaysia Using Box Jenkins Sarima Application South Asian Journal of Tourism and Heritage, Vol. 3, Number 2

Mao, Q., Zhang, K., Yan, W., \& Cheng, C. (2018). Forecasting the incidence of tuberculosis in China using the seasonal auto-regressive integrated moving average (SARIMA) model. Journal of Infection and Public Health.

Oliveira, P. J., Steffen, J. L., \& Cheung, P. (2017). Parameter Estimation of Seasonal Arima Models for Water Demand Forecasting Using the Harmony Search Algorithm. Procedia Engineering, 186, 177-185.

Oscar Claveria, E. M. a. S. T. (2014). Tourism Demand Forecasting with Neural Network Models: Different Ways of Treating Information. International Journal of Tourism Research, 17(5), 492-500.

Palmer, A., José Montaño, J., \& Sesé, A. (2006). Designing an Artificial Neural Network for Forecasting Tourism Time Series. Tourism Management, 27(5), 781-790.

Peng, B., Song, H., \& Crouch, G. I. (2014). A Meta-Analysis of International Tourism Demand Forecasting and Implications for Practice. Tourism Management, 45, 181-193.

Shareef, R., \& McAleer, M. (2007). Modelling the Uncertainty in Monthly International Tourist Arrivals to Maldives. Tourism Management, 28(1), 23-45.

Smith, B. L., Williams, B. M., \& Keith Oswald, R. (2002). Comparison of Parametric and Nonparametric Models for Traffic Flow Forecasting. Transportation Research Part C: Emerging Technologies, 10(4), 303-321.

Song, H., Li, G., Witt, S. F., \& Athanasopoulos, G. (2011). Forecasting Tourist Arrivals using Time-Varying Parameter Structural Time Series Models. International Journal of Forecasting, 27(3), 855-869. 